\title{
Identification of hoxb1b downstream genes: hoxb1b as a regulatory factor controlling transcriptional networks and cell movement during zebrafish gastrulation
}

\author{
WILLEM M.R. VAN DEN AKKER ${ }^{*, 1,2}$, ANTONY J. DURSTON ${ }^{2,3}$ and HERMAN P. SPAINK ${ }^{3}$ \\ ${ }^{1}$ Max Planck Institute for Biophysical Chemistry, Department of Molecular Cell Biology, Göttingen, Ger- \\ many, ${ }^{2}$ Hubrecht Institute, Developmental Biology and Stem Cell Research, Utrecht, The Netherlands and \\ ${ }^{3}$ Institute of Biology, Leiden University, Leiden, The Netherlands
}

\begin{abstract}
Hox proteins are homeobox containing transcription factors that play important roles in patterning the presumptive central nervous system and the axial mesoderm in the early vertebrate embryo. Hox genes are first expressed during gastrula stages and recent studies suggest that their function goes beyond their role as patterning determinants. To improve our understanding of the role of Hox proteins during early vertebrate development, we designed a strategy to identify target genes of the zebrafish hoxb1b using overexpression and whole-genome microarray analysis. We directly compared the hoxb1b microarray data with those resulting from heterologous over-expression of the Xenopus XhoxD1 gene in zebrafish embryos. Both genes are the first expressed hox genes in their respective native embryos and display similar spatial expression patterns. The zebrafish transcriptome was analysed prior to the start of the expression of the endogenous hoxb1b gene and we observed extensive overlap between the hoxb1b and XhoxD1 putative downstream genes suggesting evolutionary functional conservation between these hox genes. Furthermore, genes encoding transcription factors and proteins that are known to be involved in cell adhesion and movement were over-represented among the candidate downstream genes, indicating the involvement of the developmentally earliest expressed hox genes in transcriptional networks and cell movement processes.
\end{abstract}

KEY WORDS: hox gene, downstream target gene, gastrulation, zebrafish, microarray

\section{Introduction}

During vertebrate gastrulation, the three definitive germ layers are formed and the anterior-posterior $(\mathrm{A} / \mathrm{P})$ axis of the embryo is determined. This complex process is characterised by extensive cell movements and patterning of tissues. Various lines of evidence have shown that hox genes, which encode homeobox transcription factors, play important roles in patterning during gastrulation (limura and Pourquie, 2006; Wacker et al., 2004). It has recently also been suggested that they are involved in regulating cell migration (limura and Pourquie, 2006; limura and Pourquie, 2007).

In most vertebrates, hox genes are located in four clusters in the genome (Duboule, 2007; Garcia-Fernandez, 2005). Because of the whole-genome duplication event in the Actinopterygii (ray- finned fishes) leading to the teleost lineage (Hurley et al., 2007), the zebrafish harbours eight hox clusters (Corredor-Adamez et al., 2005; Postlethwait et al., 2000) of which one is reduced to a single microRNA (Woltering and Durston, 2006). The generalised hypothesis is that the hox genes are expressed in a spatial and temporal fashion according to their position in a cluster ((Duboule and Dolle, 1989; Graham et al., 1989; Izpisua-Belmonte et al., 1991) reviewed by (Deschamps and van Nes, 2005)). In case of the frog Xenopus laevis, the first hox genes are expressed in the non-organiser mesoderm of the gastrula ((Wacker et al., 2004) and references herein) and, upon involution of the mesoderm, transient hox expression seems to be stabilised via an interaction

\footnotetext{
Abbreviations used in this paper: A/P, anterior/posterior;
}

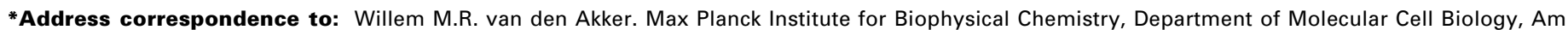
Fassberg 9, D-37077, Göttingen, Germany. Fax: +49-551-201-1504. e-mail: wakker@gwdg.de
}

Supplementary Material for this paper (figure) is available at: http://dx.doi.org/10.1387/ijdb.082678wv 


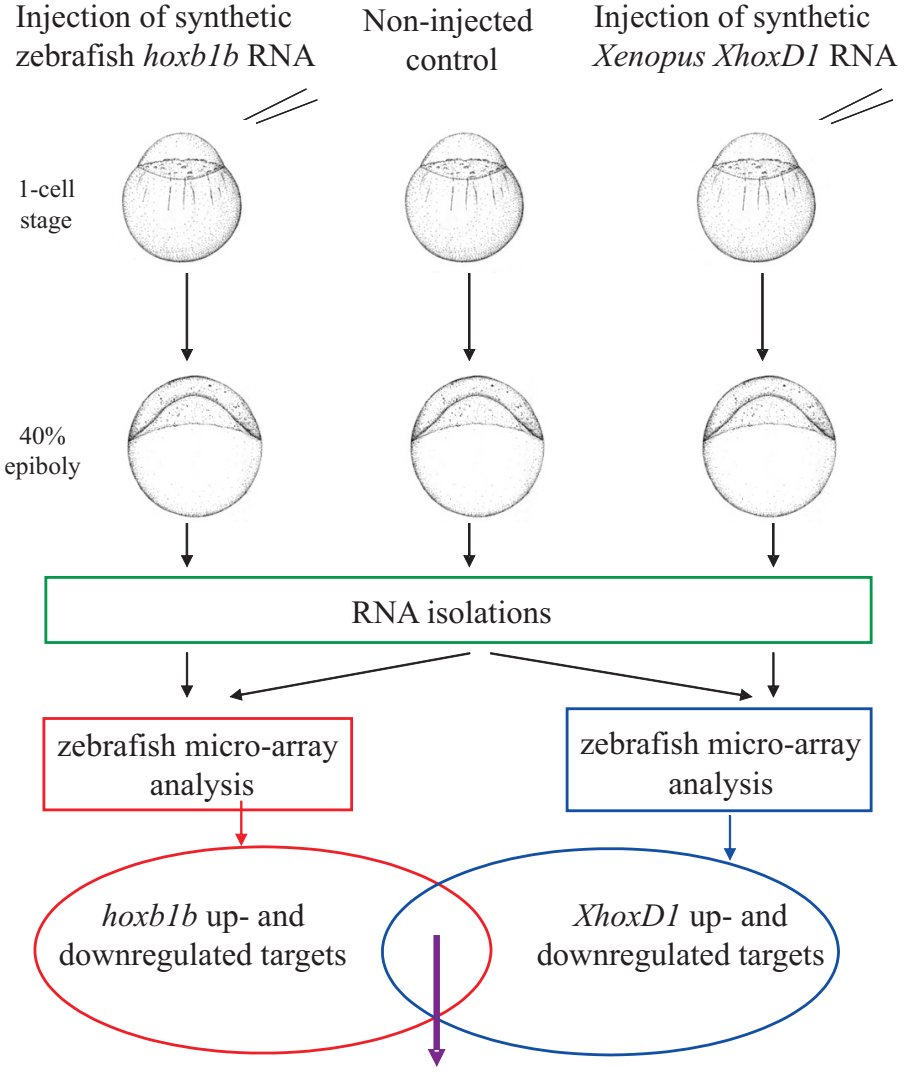

overlap used for further analyses

Fig. 1. Flow diagram of the experimental set-up of this study. See text for details.

with the Spemann organiser (the 'time-space translator model', (Jansen et al., 2007; Wacker et al., 2004)). The specific combination of expressed hox genes (the 'hox code', (Kessel and Gruss, 1991)) of the involuted mesoderm is transferred in a temporally and spatially specific manner to the overlying posterior neuroec- toderm by which this tissue becomes patterned in the A/P axis of the embryo. Comparison with other model species suggests that this scenario has a broader significance as demonstrated by the behaviour of hox gene expression in for example mouse (Forlani et al., 2003) and chicken (limura and Pourquie, 2006) embryos.

Recently, it was demonstrated that some hox genes might be actively involved in cell migratory events in the gastrula. Cells of the chicken epiblast layer in the anterior primitive streak region containing the artificially expressed Hoxb1 gene, ingressed into the mesodermal layer and migrated anteriorly, while HoxB9 expressing cells did not migrate or displayed only limited movements (limura and Pourquie, 2006). The molecular understanding of these various functions of hox genes during gastrulation is very limited. Since Hox proteins control the transcriptional activity of target genes, the identification of these downstream genes is an important step in elucidating the molecular hox functions. One strategy for identifying hox downstream genes is to analyse the transcriptosomal consequences of hox gene abrogation in a gastrula. This option is partially hampered by functional redundancy among hox genes (Greer et al., 2000; McClintock et al., 2002; Rossel and Capecchi, 1999; Studer et al., 1998). Notably, hox genes having equivalent positions in different hox clusters and making up what is called a paralogue group (PG), can share particular functions, as becomes apparent when the simultaneous abrogation of two or three PG gene members displays a stronger phenotype than the additive effects of inactivation of individual members (e.g.(van den Akker et al., 2001) (McNulty et al., 2005)).

In the present study, we applied a gain-of-function approach to identify downstream genes of the developmentally first expressed zebrafish hox gene, hoxb1b (formerly hoxa-1, Alexandre et al., 1996). To further select for hox-target gene interactions that are active during the earliest developmental stages, we made use of the supposed evolutionary conservation of the function of hox genes during gastrulation. For this we performed a direct comparison between the transcriptosomal changes upon the over-expression of the zebrafish hoxb1bgene and the heterologous overexpression of the first-expressed Xenopus laevis hox gene (XhoxD1) in zebrafish embryos. Four candidate target genes

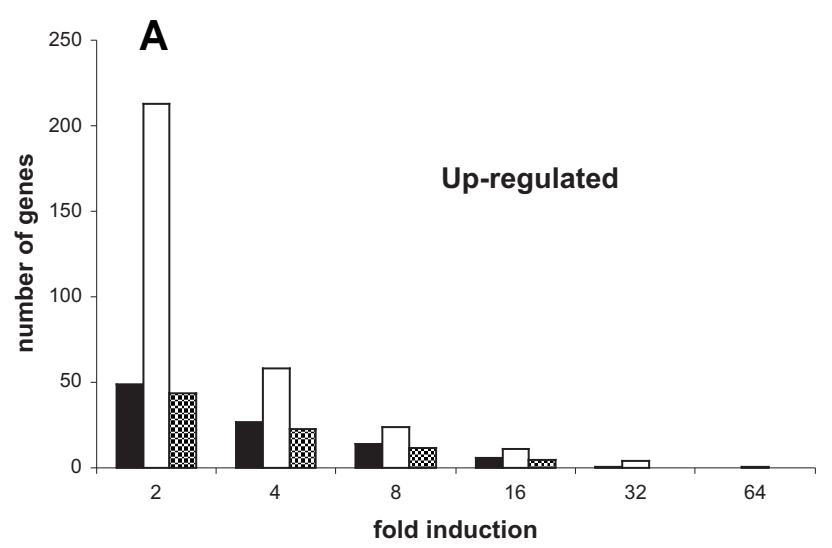

B

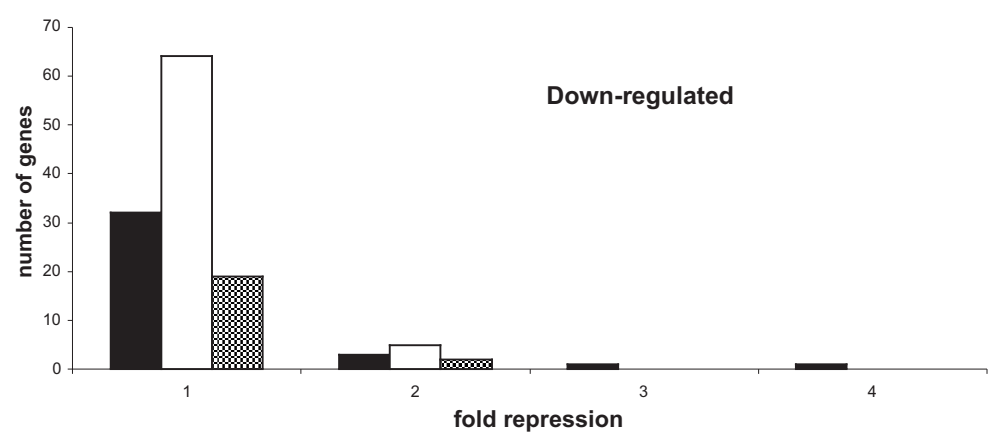

Fig. 2. Comparison of the number of identified hoxb1b and XhoxD1 downstream genes and those identified as common to both hox genes. Shown are the number of genes whose transcript levels were up-regulated (A) or down-regulated (B) by zebrafish hoxb1b (black bar) and Xenopus XhoxD1 (white bar) over-expression as determined by microarray analysis. The number of identified genes shared by both hox genes are shown by a blocked bar. Results are shown for common signature sets from all combined duplicate experiments and sorted according to their minimal fold of induction or repression using a $P$ value filter of $e^{-5}$. 
TABLE 1

\section{GENES UPREGULATED BY OVER-EXPRESSION OF ZEBRAFISH HOXB1B AND XENOPUS XHOXD1 IN ZEBRAFISH EMBRYOS AND ANALYSED AT 40\% EPIBOLY}

\begin{tabular}{|c|c|c|c|c|c|}
\hline Accession number & Gene name or putative identity & Unigene & Function and/or process & Ratio & P-value \\
\hline U40995 & hoxb1b; homeo box B1b & Dr.83048 & transcription factor & $10.4^{\star}$ & 7.E-10 \\
\hline BI879735 & putative neurogranin & Dr.81838 & signal transduction & 6.6 & $5 . \mathrm{E}-19$ \\
\hline Al878133 & similar to coronin, actin binding protein, 1c (LOC562849) & Dr.76191 & cytoskeletal regulation & 3.0 & 3.E-30 \\
\hline Bl671271 & hypothetical LOC558422; similar to lipin & Dr.6402 & nuclear phosphatase & 2.6 & 2.E-07 \\
\hline Al601294 & similar to dynein, cytoplasmic 1, intermediate chain 1 (LOC799392) & Dr.77888 & microtubule-based movement & 7.1 & 4.E-15 \\
\hline BI866278 & putative brain-specific angiogenesis inhibitor 1 precursor & Dr.81102 & G-protein coupled receptor protein signalling pathway & 8.3 & 2.E-21 \\
\hline BI981287 & putative cyclin-dependent kinase 5, regulatory subunit 1 & no entry & cell cycle regulation & 3.8 & 3.E-20 \\
\hline $\mathrm{B} 1840896$ & bhlhb5; basic helix-loop-helix domain containing, class B, 5 & Dr.84568 & transcription factor & 17.4 & 3. E-43 \\
\hline Al721647 & nr2e 1; nuclear receptor subfamily 2, group E, member 1 & Dr.78647 & nuclear receptor & 6.8 & 7.E-13 \\
\hline BM184118 & ndor1; nadph dependent diflavin oxidoreductase 1 & Dr.32954 & oxidoreductase activity & 2.3 & 3.E-17 \\
\hline AF007949 & ret1; receptor tyrosine kinase & Dr.75763 & signal transduction & 5.0 & 4.E-11 \\
\hline AJ290391 & bcdo2l; beta-carotene 15, 15-dioxygenase 2, like & Dr.79440 & oxidoreductase activity & 2.8 & 7.E-09 \\
\hline AF001909 & rx3; retinal homeobox gene 3 & Dr.540 & transcription factor & 7.0 & 8.E-12 \\
\hline U50563 & msxe; muscle segment homeobox e & Dr.75086 & transcription factor & 3.0 & 2.E-11 \\
\hline BI473045 & sst3; somatostatin 3 & Dr.82638 & regulation of cell migration & 3.6 & 5.E-08 \\
\hline U67844 & dlx6a: distal-less homeobox gene $6 a$ & Dr.75092 & transcription factor & 2.8 & 6.E-09 \\
\hline Al793690 & dmbx1a; diencephalon/mesencephalon homeobox $1 a$ & Dr.78986 & transcription factor & 26.6 & 3. E-16 \\
\hline BG308656 & zgc:73361; putative reprimo-like & Dr.27132 & cell cycle & 16.1 & 2.E-14 \\
\hline BI879533 & pcdh10b; protocadherin $10 \mathrm{~b}$ & Dr.82621 & cell adhesion & 5.8 & $9 . \mathrm{E}-17$ \\
\hline BE015653 & gad1; glutamate decarboxylase 1 & Dr.81985 & neurotransmitter biosynthetic process & 5.1 & 2.E-07 \\
\hline BG306206 & phlda3; pleckstrin homology-like domain, family A, member 3 & Dr.82918 & apoptosis & 2.4 & 2.E-19 \\
\hline BM155603 & putative $n k x 6.2$ & Dr.15365 & transcription factor & 18.9 & 4. E-11 \\
\hline Al641124 & cxcl12b; chemokine (C-X-C motif) ligand 12b (stromal cell-derived factor 1 ) & Dr.105027 & chemokine ligand & 6.8 & $<1 . E-50$ \\
\hline Al793487 & sp8l; sp8 transcription factor-like (sp8a) & Dr.29744 & transcription factor & 4.4 & 3.E-09 \\
\hline BE016629 & putative cytokine receptor-like factor 1 & Dr.32094 & receptor activity & 3.3 & 1.E-07 \\
\hline AF228334 & hand2; heart and neural crest derivatives expressed 2 & Dr.81423 & transcription factor & 14.5 & 2.E-13 \\
\hline L25273 & alcam; activated leukocyte cell adhesion molecule & Dr.20912 & cell adhesion & 11.6 & 5.E-09 \\
\hline В1979064 & sp9: sp9 transcription factor & Dr.86028 & transcription factor & 11.9 & 6. E-33 \\
\hline Al626641 & putative long-chain-fatty-acid-CoA ligase 6 & Dr.185 & lipid biosynthesis & 9.9 & 4.E-17 \\
\hline CO801543 & si:ch211-15406.6; c type lectin domain family 4 member & Dr.73909 & carbohydrate binding & 4.1 & 1.E-06 \\
\hline
\end{tabular}

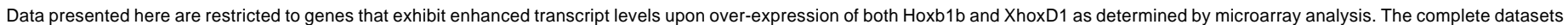

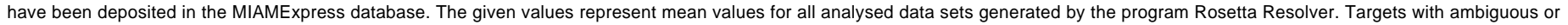
unknown function are left out of the figure to improve legibility. The order of targets in this Table is such that it harmonizes with the data presented in Supplementary Figure S1.

* Since the injected hoxb1b plasmid contained the sequence of the oligonucleotide representing zebrafish hoxb1b on the microarray only data for XhoxD1 are given.

were selected for further study by in-situ hybridization analysis and we confirmed that all of these genes are targets of the zebrafish hoxb1b gene as well as targets of the closely related paralogous hoxb1a gene. Our results are in agreement with the hypothesis that hox genes are involved both in controlling patterning events as well as in regulating cell movements during the earliest stages of vertebrate development. Moreover, the identification of a series of putative hox-downstream genes reported here provides a fertile basis for the further molecular understanding of the mechanisms underlying the early embryonic developmental events.

\section{Results}

\section{Experimental rationale of this study}

To gain insight into the functions of hox genes during early embryogenesis we set up a strategy to identify downstream genes of the developmentally first expressed hox gene in zebrafish, hoxb1b. For this, we combined hox over-expression in zebrafish embryos with whole-genome microarray analysis and compared the data obtained with those that were found when the first expressed Xenopus hox gene, XhoxD1, was heterologously expressed in zebrafish embryos (Fig. 1). Synthetic RNA of both hox genes was microinjected into 1-cell stage embryos and the total RNA of the developing embryos was harvested at $40 \%$ epiboly. This time point is just before the start of the endogenous transcription of hoxb1b at $50 \%$ epiboly (Alexandre et al., 1996; Maves and Kimmel, 2005). The choice of this analysis time point eliminates the background effect of endogenously expressed hoxb $1 b$ while at the same time the embryonic environment is very closely related to that where hoxb $1 b$ is naturally first expressed. We anticipated that the direct comparison of the effects of hoxb1b and XhoxD1 over-expression reduces the number of false positive target genes and offers the possibility to detect shared target genes which might expose evolutionarily conserved functions of the first expressed hox genes in developing embryos.

\section{Extensive overlap between hoxb1b and XhoxD1 downstream genes}

Analysis of the microarray data (see Materials and Methods section for technical details) showed that there are significantly more zebrafish genes affected by the forced expression of the XhoxD1 gene than by the zebrafish hoxb1b gene (Fig. 2). Of the 49 genes that are more than two-fold induced by hoxb $1 b$, nearly $90 \%$ are also present among the collection of 213 XhoxD1 induced genes. The percentage of common hoxb1b/XhoxD1 
A



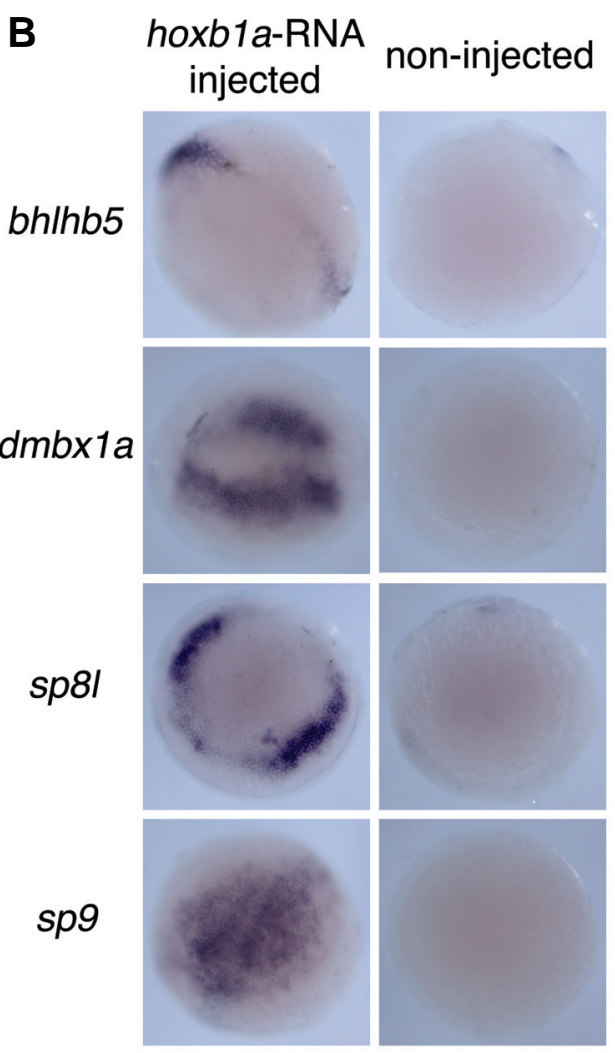

Fig. 3. Induced expression of transcription factors after the forced expression of hoxb1b and hoxb1a in zebrafish embryos. Synthetic hoxb1b (150 pg) (A) or hoxb1a (50 pg) (B) RNA was microinjected into 1-cell stage embryos. At 50\% epiboly, the embryos were analysed for the presence of bhlhb5, dmbx1a, sp8l and sp9 transcripts by in-situ hybridization. Non-injected hybridized control embryos are shown on the right sides.

induced genes among the total number of XhoxD1 up-regulated genes increases from $21 \%$ at 2 -fold induction to $40 \%$ at 4 -fold induction, and $50 \%$ at 8 -fold induction. Similar results were obtained for the hoxb1b and XhoxD1 down-regulated genes. Regarding the genes exhibiting at least two-fold reduced transcript levels about $60 \%$ of the 32 hoxb 1 b down-regulated genes are also identified in the collection of 64 genes down-regulated by XhoxD1. Therefore, it seems that the more strongly the expression level of a putative target gene is influenced by hox-overexpression, the more likely that it is a common target gene of both hox genes. Taken together, these data demonstrate that hoxb1b and XhoxD1 have many downstream genes in common following their forced expression early during zebrafish development.

\section{Endogenous expression of hoxb1b/XhoxD1 downstream genes}

Since we have applied a gain-offunction approach in this study, it is of importance to check whether the identified potential hox-target genes are expressed under physiological (normal) conditions during early development. For this we have made use of the data obtained in the study of Mathavan and colleagues (Mathavan et al., 2005) who determined the temporal transcriptional expression levels during embryonic zebrafish development using the same microarray platform as applied in the present study, allowing direct comparison between data sets. The reliability of the Mathavan et al. dataset was recently confirmed in an independent study published by Ouyang and colleagues (Ouyang et al., 2008). The data presented in Supplementary Figure S1 visualise the endogenous temporal expression profiles of the up-regulated and downregulated genes from the common hoxb1b/XhoxD1 downstream gene target set. As expected, all down-regulated genes exhibit early native developmental expression, whereas several of the positively regulated genes are clearly expressed prematurely by the forced hox gene expression. It might be that some of

TABLE 2

\section{GENES DOWN-REGULATED BY OVER-EXPRESSION OF ZEBRAFISH HOXB1B AND XENOPUS XHOXD1 IN ZEBRAFISH EMBRYOS AND ANALYSED AT 40\% EPIBOLY}

\begin{tabular}{|c|c|c|c|c|c|}
\hline Accesión number & Gene name or putative identity & Unigene & Function and/or process & Ratio & P-value \\
\hline X71845 & eve1; even-skipped-like1 & Dr.75074 & transcription factor & -3.0 & 2.E-07 \\
\hline BI885265 & putative Desmoglein & no entry & cell adhesion & -3.8 & 1.E-06 \\
\hline Al477935 & zgc:110712, hypothetical protein LOC550250; Protein family: keratin type 1 cytoskeletal cytokeratin & Dr.33453 & cytoskeleton & -3.6 & 2.E-10 \\
\hline AW077995 & ptgs2a; prostaglandin-endoperoxide synthase $2 a$ & Dr.113864 & cell migration, prostaglandin biosynthesis & -2.6 & 8.E-08 \\
\hline $\mathrm{B} \mid 850015$ & Hypothetical protein LOC794352; putative zinc finger protein 36 homolog & Dr.34611 & transcription factor & -2.0 & 6.E-06 \\
\hline Al477963 & si:ch211-191a24.3; putative tensin & Dr.77015 & cell migration & -2.5 & 3.E-07 \\
\hline AW344023 & CD44 homolog membrane glycoprotein precursor & Dr.122381 & cell adhesion & -2.1 & 9.E-08 \\
\hline AF301264 & her9; hairy-related 9 & Dr.78757 & transcription factor & -5.6 & 3.E-09 \\
\hline AW019321 & zgc:92414; putative urate oxidase & Dr.106461 & metabolism & -2.3 & 3.E-12 \\
\hline Al721923 & zgc:136396; putative collagenase 3 precursor & Dr.78814 & cell adhesion & -3.3 & 2.E-06 \\
\hline
\end{tabular}

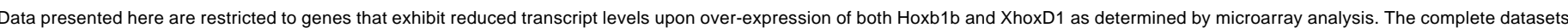

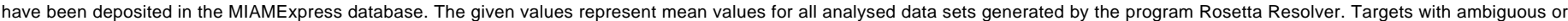
unknown function are left out of the figure to improve legibility. The order of targets in this Table is such that it harmonizes with the data presented in Supplementary Figure S1. 
these latter interactions are functional during other stages of normal development (for example in the developing hindbrain) or during adulthood.

\section{Spatially restricted expression of some hoxb1b/hoxb1a in- duced transcription factors}

To validate the microarray data we tested the transcriptional activation of several identified putative downstream genes of hoxb1b and XhoxD1 by zebrafish whole-mount in-situ hybridization. The four target genes selected, sp8/ and'sp9 (two members of the Sp1 family of zinc-finger transcription factors (Kawakami et al., 2004), dmbx1a (a homeobox-encoding gene, ((Kawahara et al., 2002); also known as $\mathrm{mbx}$ ) and bhlhb5 (a bHLH-encoding gene, (Adolf et al., 2004), all encode transcription factors and are all transcribed in presumptive rhombencephalic tissues. These tissues are patterned by transcription factor networks in which hox genes exert a central function. In addition, the structurally closely related $s p 8 /$ and $s p 9$ genes as well as the other members of the sp1-family appear to be chromosomally linked to the various hox clusters, which might hint at a special relationship between $s p$ and hox genes. Over-expression of hoxb1b early during zebrafish development did indeed induce the expression of all four putative target genes as expected from the microarray analyses (Fig. 3A). Moreover, these four genes were also induced by the ectopic expression of the zebrafish PG1 member hoxb1a (its endogenous expression starts around $9 \mathrm{hpf}$, at the transition of gastrulation to the segmentation stage (Maves and Kimmel, 2005)) as analyzed at the germ-ring stage of zebrafish development (Fig. 3B). This observation that different but related Hox proteins might have common downstream genes corroborates the proposal that the zebrafish hoxb1b and hoxb1a genes have partially redundant functions (McClintock et al., 2001). Interestingly, the induced expression domains of bhlhb5, dmbx1a, sp8I and sp9 each display spatially restricted expression in the developing zebrafish embryo following ubiquitous over-expression of'hoxb1b/hoxb1a (Fig. 3). This indicates that the presence of PG1 hox genes is not the limiting factor in determining the localised expression of these downstream genes in the developing embryo at the stages studied, and it hints at the spatially restricted activities of factors that are positively or negatively involved in the transcriptional regulation of these downstream genes. In the case of hox-target genes whose transcriptional regulation is directly controlled by Hox proteins, spatial restriction of Hox-co-factors, like members of the Meis family, is a plausible explanation for the observed restricted expression domains of the target genes.

\section{Relative abundance of morphogenetic regulators and tran- scription factors among target genes}

Gene annotation of the hoxb1b/XhoxD1 overlap group of positively and negatively regulated downstream genes shows an over-representation of genes encoding transcription factors and of genes that encode factors associated with cell adhesion and cell-movement processes (positively-regulated targets: 15/29 (52\%); negatively-regulated targets: 9/10 (90\%), Tables 1,2; Fig.4). These data support the idea that the first expressed hox genes have a role both in patterning and in regulating cell movements early during development.

Furthermore, we detected a strong up-regulation of hoxb1b
A

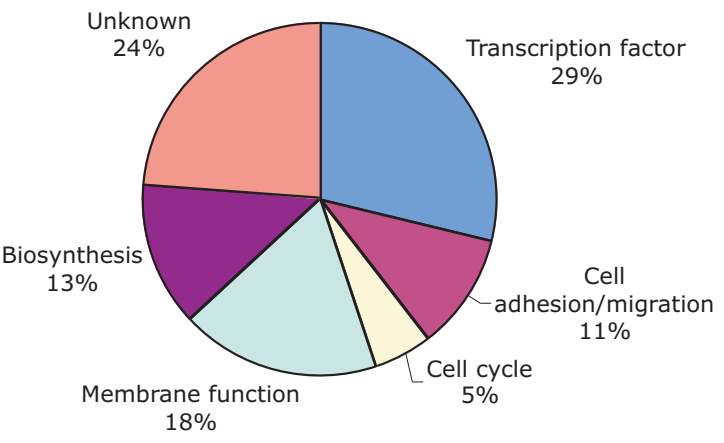

B

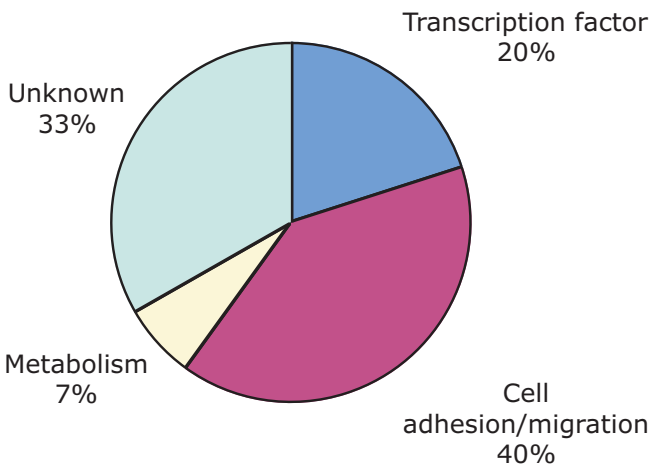

Fig. 4. Classification of the identified common hoxb1b/XhoxD1 putative target genes. The relative presence of both induced (A) and repressed (B) common hoxb1b/XhoxD1 target genes are grouped according to their supposed biological functions.

upon over-expression of XhoxD1, possibly involving Hox-hox cross-regulation (or auto-regulation) (Hooiveld et al., 1999). Our data do not allow conclusions about hoxb1b-hoxb1b interactions since the oligonucleotide sequence on the array is present within the injected over-expression construct. Since no other hox genes are significantly induced in our experiments, we assume that the identified target genes are downstream genes of the first developmentally expressed hox genes and not (indirectly) induced via other hox genes.

\section{Discussion}

Gastrulation is a complex developmental process that all metazoan embryos have to go through. The identity of the hoxdownstream genes identified in this study supports the idea that hox genes exert a role in patterning as well as in cell behavioural activities during this process. Comparison of zebrafish microarray gene expression profiles between the forced expression of zebrafish hoxb1b and Xenopus XhoxD1, revealed extensive overlap in their downstream genes indicating partial evolutionary conservation of Hox functions. A possible explanation for the incompleteness of this overlap is that particular Hox functions are differently distributed over PG1 hox members in diverse species. In this respect it is of interest that most effects of the simultaneous knock-down of all PG1 Hox members in Xenopus laevis could be overcome by XhoxD1 over-expression in these Xenopus 
morphants indicating a broad functional spectrum for this particular hox gene (McNulty et al., 2005). According to a similar line of reasoning, the lower number of identified hoxb1b downstream genes in comparison with those of XhoxD1 might imply a more restricted function for hoxb1b. Alternatively, or additionally, evolutionary differences in the roles of the first expressed hox genes may exist between the fish and frog lineages which have an evolutionary divergence time of more than 400 million years (Prince and Pickett, 2002).

Comparison of the potential hox target genes identified here with their temporal endogenous expression profiles during embryogenesis (Mathavan et al., 2005) displays several apparent discrepancies. This is presumably an intrinsic consequence of the over-expression approach we applied. Firstly, the forced expression is performed before the endogenous expression of hoxb1b. Secondly, the forced expression of the hox genes is ubiquitous in the embryo and not restricted to the ventrolateral gastrula mesoderm in which tissue the first endogenous expression of hox genes takes place. So there seems to be a permissive environment for transcriptional regulation of various genes in which the artificially expressed hox gene is a limiting factor. This explains why several of the interactions identified are not necessarily functional during the earliest stages of normal development but may be during later developmental processes.

Members of the TALE subclass of homeodomain proteins, Meis and $\mathrm{Pbx}$, have been reported to be functional in modulating the transcriptional activity of Hox proteins in vertebrates (Moens and Selleri, 2006; Pearson et al., 2005), including zebrafish (Choe and Sagerstrom, 2005; Vlachakis et al., 2001). Since the meis genes are expressed starting at $50 \%$ epiboly (Zebrafish Gene Expression Database, ZFIN), we do not expect that Meis proteins play a role in modulating the transcriptional activity of the Hox downstream genes identified here. Members of the $p b x$ class (pbx2, pbx3b, pbx4, pknox1.1 and pknox1.2), however, are ubiquitously expressed from the 1-cell stage onwards during early zebrafish development (Zebrafish Gene Expression Database, ZFIN) and are possibly involved in the transcriptional regulation of downstream targets of hoxb1b reported here. Our observations that some Hox target genes are not uniformly expressed in the embryo following forced expression might be explained by the spatially restricted activity of modulators of hox target gene expression at this stage of development or, alternatively, the result may imply that these downstream genes are not directly transcriptionally activated by Hoxb1b. Over the last few years, it has become evident that microRNAs exert important functions in gene regulation, including that of hox genes (reviewed by (Begemann, 2008)) Such control mechanisms might well be involved in the explanation of the spatial expression of hox-target genes that we report here. We can envisage a direct role of spatially-restricted microRNA mediated down regulation of the injected hox RNA, or otherwise regulation of the target gene itself (or an indirect effect by affecting a regulatory gene for this target gene).

The relative abundance of transcription factors and components that are involved in cell-cell interactions among the identified Hoxb1b target genes might indicate an involvement of this protein in patterning (specification) as well as cell in behavioural processes. A recent study in the invertebrate Drosophila indicates that the Hox target genes can be separated into directly regulated transcription factors and signalling molecules (regulator genes), and that most indirectly regulated genes (realisator genes) are involved in cell adhesion, polarity and cytoskeleton (Lovegrove et al., 2006). This fits with the hypothesis that Hox proteins play an active role in the complex cell movements taking place in the (pre)gastrula of which epiboly and mesodermal ingression are the most prominent.

Recently, Rohrschneider and collegues (Rohrschneider et al., 2007) published a study on Hoxb1a downstream genes applying a loss-of-function approach using Morpholinos and focussing on the consequences for zebrafish rhombomere 4 characteristics at 19-20 hpf. It is striking that no overlap exists between their identified target genes of hoxb1a and our target genes (both studies made use of the same oligo-set for microarray analysis) and the target genes identified in the present study (both studies made use of the same oligo-set for microarray analysis). This might be explained in part by the differences between hoxb1a and hoxb1b, but we suppose that the temporal and tissue specific differences in the analyses are most crucial here, demonstrating the changing nature and the complexity of hox gene functions during development.

\section{Conclusions}

Despite the broad and strong interest in the functions of hox genes as transcriptional regulators, the identification of their downstream target genes appears to be quite resistant to being fully elucidated (Svingen and Tonissen, 2006). The large number of hox genes, their partially simultaneous expression and their partially redundant functions are only a few of the reasons making this a complex issue to investigate. Here, we report the identification of putative hox-downstream genes by the combination of forced expression early during development and microarray analyses. We were in part able to focus the range of identified hox downstream genes to the early developmental stages by the direct comparison of the effects of over-expression analysing two first expressed hox genes from distantly related organisms (zebrafish and Xenopus). This approach was chosen to select for evolutionary conserved mechanisms. Analysis of the categories of putative hox-target genes suggests that the earliest hox functions are related to processes involving patterning and cell movement, fitting well with the (pre-)gastrula stage processes in which hoxgenes are thought to be involved. The identification of putative downstream genes reported here is an important step in elucidating the molecular mechanisms of hox gene functions in the early stages of vertebrate development. Study of the individual candidate genes in relation to hox functions will further delineate the earliest steps in vertebrate development.

\section{Materials and Methods}

\section{Overexpression of hox genes in zebrafish embryos}

Fertilized zebrafish eggs were obtained from natural spawnings, raised under standard conditions (Westerfield, 1995) and staged according to Kimmel et al. (Kimmel et al., 1995). The zebrafish pCS2hoxb1b and pCS2hoxb1a constructs (McClintock et al., 2001) (a kind gift of V. Prince, Chicago) were used for over-expression experiments. Previously, we described the Xenopus laevis XHoxD1 over-expression construct (McNulty et al., 2005). Capped RNA was synthesized in vitro using the mMessage mMachine kit (Ambion) according to the manufacturer's instructions. The 
RNA was purified via a RNAeasy column (Qiagen) and microinjected into 1 -cell stage embryos in a volume of $1 \mathrm{nl}$ containing 50 or $150 \mathrm{pg}$ RNA.

\section{Zebrafish microarray analysis}

Zebrafish microarray analysis was performed using 16,416 custom spotted 65-mer oligonucleotides designed by Compugen and synthesised by Sigma-Genosys (Mathavan et al., 2005). Additionally, a set of 340 custom-made oligonucleotides representing all zebrafish hox genes, various small GTPases, genes of the innate immune system and a set of lectin genes was spotted. A two-colour ratio methodology was applied to compare hox-RNA-injected embryos with non-injected ('control') embryos, essentially as described previously (Meijer et al., 2005). It is noted that the use of non-injected embryos as controls does not rule out a possible effect induced by the injection of RNA itself. Total RNA from $40 \%$ epiboly stage zebrafish embryos was isolated using the TRIzol reagent (Invitrogen) and purified as described previously (Meijer et al., 2005). For biological duplicate experiments, hox RNA was independently prepared and a different batch of zebrafish eggs was used. The reproducibility was demonstrated with hoxb1b RNA that gave similar results in the microarray analysis. The combined data sets from the three biological and several technical duplicates in these experiments were analyzed for the number of statistically significant up or down regulated genes with a threshold value $P$ of $e^{-5}$. The microarray data were analyzed further with the Rosetta Resolver software package (version 6, Rosetta Impharmatics LLC). Selection of signature sequences was based on at least four replicates per experiment. Primary data sets have been deposited in the MIAMExpress database (accession number E-MEXP-1426).

\section{Genomic and expression databases}

Gene annotation of the microarray oligonucleotides was performed manually using the Ensemble zebrafish genome assembly version 6 (Zv6) and the Zebrafish Model Organism Database (ZFIN). In case of ambiguity of gene annotation these data were only included in the supplementary datasets. Classification of genes was based on the Unigene database (NCBI). Information about developmental gene expression was in part derived from the ZFIN database.

\section{Whole-mount in situ hybridisation}

For whole-mount in situ hybridisation (ISH) embryos were fixed in $4 \%$ paraformaldehyde and stored in methanol. ISH was performed essentially as described by Thisse and colleagues (Thisse et al., 2004). Anti-sense RNA in-situ probes were synthesized using T7 or Sp6 RNA polymerase and labelled with digoxigenin. The following zebrafish Expressed Sequence Tags (ESTs, provided by the IMAGE Consortium) were used for the preparation of in-situ antisense probes: bhlhb5 [GenBank:BI840896], dmbx1a [GenBank:Al793690], sp8/(sp8a) [GenBank:CA470674] and sp9 [GenBank:CA475616]. The identities of the ESTs were checked by sequencing. Linearization was done with Sall (bh/hb5 and dmbx1a), Pvull $(s p 8)$ and $K p n l(s p 9)$, and transcription was performed using Sp6 (bh/hb5 and $d m b x 1 a)$ or T7 (sp8l and $s p 9)$. Detection of the anti-digoxigenin antibody-alkaline phosphatase conjugate was done using BM-Purple (Roche). Embryos were mounted in $90 \%$ glycerol and photographed using a compound microscope.

\section{Acknowledgements}

Dr. Victoria E. Prince is thanked for the generous gift of the zebrafish hox over-expression constructs. Dr. Annemarie H. Meijer is acknowledged for technical advice. We thank the colleagues from the zebrafish facility at the Hubrecht Institute for their help. This work was financially supported by the European Commission $6^{\text {th }}$ Framework Program (LSHG-CT-2003-503496, ZF-MODELS) and the European Union (LHSM-CT-2003-504468).

\section{References}

ADOLF, B., BELLIPANNI, G., HUBER, V. and BALLY-CUIF, L. (2004). atoh1.2 and beta3.1 are two new bHLH-encoding genes expressed in selective precursor cells of the zebrafish anterior hindbrain. Gene Expr Patterns 5: 35-41.

ALEXANDRE, D., CLARKE, J.D., OXTOBY, E., YAN, Y.L., JOWETT, T. and HOLDER, N. (1996). Ectopic expression of Hoxa-1 in the zebrafish alters the fate of the mandibular arch neural crest and phenocopies a retinoic acidinduced phenotype. Development 122: 735-746.

BEGEMANN, G. (2008). MicroRNAs and RNA interference in zebrafish development. Zebrafish 5: 111-119.

CHOE, S.K. and SAGERSTROM, C.G. (2005). Variable Meis-dependence among paralog group-1 Hox proteins. Biochem Biophys Res Commun 331: 1384-1391.

CORREDOR-ADAMEZ, M., WELTEN, M.C., SPAINK, H.P., JEFFERY, J.E., SCHOON, R.T., DE BAKKER, M.A., BAGOWSKI, C.P., MEIJER, A.H., VERBEEK, F.J. and RICHARDSON, M.K. (2005). Genomic annotation and transcriptome analysis of the zebrafish (Danio rerio) hox complex with description of a novel member, hox b 13a. Evol Dev 7: 362-375.

DESCHAMPS, J. and VAN NES, J. (2005). Developmental regulation of the Hox genes during axial morphogenesis in the mouse. Development 132: 2931-2942.

DUBOULE, D. (2007). The rise and fall of Hox gene clusters. Development 134 2549-2560.

DUBOULE, D. and DOLLE, P. (1989). The structural and functional organization of the murine HOX gene family resembles that of Drosophila homeotic genes. EMBO J 8: 1497-1505.

FORLANI, S., LAWSON, K.A. and DESCHAMPS, J. (2003). Acquisition of Hox codes during gastrulation and axial elongation in the mouse embryo. Development 130: 3807-3819.

GARCIA-FERNANDEZ, J. (2005). The genesis and evolution of homeobox gene clusters. Nat Rev Genet 6: 881-892.

GRAHAM, A., PAPALOPULU, N. and KRUMLAUF, R. (1989). The murine and Drosophila homeobox gene complexes have common features of organization and expression. Cell 57: 367-378.

GREER, J.M., PUETZ, J., THOMAS, K.R. and CAPECCHI, M.R. (2000). Maintenance of functional equivalence during paralogous Hox gene evolution. Nature 403: 661-665.

HOOIVELD, M.H., MORGAN, R., IN DER RIEDEN, P., HOUTZAGER, E., PANNESE, M., DAMEN, K., BONCINELLI, E. and DURSTON, A.J. (1999). Novel interactions between vertebrate Hox genes. Int J Dev Biol 43: 665-674.

HURLEY, I.A., MUELLER, R.L., DUNN, K.A., SCHMIDT, E.J., FRIEDMAN, M., HO, R.K., PRINCE, V.E., YANG, Z., THOMAS, M.G. and COATES, M.I. (2007). A new time-scale for ray-finned fish evolution. Proc Biol Sci 274: 489-498.

IIMURA, T. and POURQUIE, O. (2006). Collinear activation of Hoxb genes during gastrulation is linked to mesoderm cell ingression. Nature 442: 568-571.

IIMURA, T. and POURQUIE, O. (2007). Hox genes in time and space during vertebrate body formation. Dev Growth Differ 49: 265-275.

IZPISUA-BELMONTE, J.C., FALKENSTEIN, H., DOLLE, P., RENUCCI, A. and DUBOULE, D. (1991). Murine genes related to the Drosophila AbdB homeotic genes are sequentially expressed during development of the posterior part of the body. EMBO J 10: 2279-2289.

JANSEN, H.J., WACKER, S.A., BARDINE, N. and DURSTON, A.J. (2007). The role of the Spemann organizer in anterior-posterior patterning of the trunk. Mech Dev 124: 668-681.

KAWAHARA, A., CHIEN, C.B. and DAWID, I.B. (2002). The homeobox gene mbx is involved in eye and tectum development. Dev Biol 248: 107-117.

KAWAKAMI, Y., ESTEBAN, C.R., MATSUI, T., RODRIGUEZ-LEON, J., KATO, S. and BELMONTE, J.C. (2004). Sp8 and Sp9, two closely related buttonhead-like transcription factors, regulate Fgf8 expression and limb outgrowth in vertebrate embryos. Development 131: 4763-4774.

KESSEL, M. and GRUSS, P. (1991). Homeotic transformations of murine vertebrae and concomitant alteration of Hox codes induced by retinoic acid. Cell 67: 89104

KIMMEL, C.B., BALLARD, W.W., KIMMEL, S.R., ULLMANN, B. and SCHILLING, T.F. (1995). Stages of embryonic development of the zebrafish. Dev Dyn 203 253-310.

LOVEGROVE, B., SIMOES, S., RIVAS, M.L., SOTILLOS, S., JOHNSON, K., KNUST, E., JACINTO, A. and HOMBRIA, J.C. (2006). Coordinated control of cell adhesion, polarity, and cytoskeleton underlies Hox-induced organogenesis 
62 W.M.R. van den Akker et al.

in Drosophila. Curr Biol 16: 2206-2216.

MATHAVAN, S., LEE, S.G., MAK, A., MILLER, L.D., MURTHY, K.R., GOVINDARAJAN, K.R., TONG, Y., WU, Y.L., LAM, S.H., YANG, H. et al. (2005). Transcriptome analysis of zebrafish embryogenesis using microarrays. PLoS Genet 1: 260-276.

MAVES, L. and KIMMEL, C.B. (2005). Dynamic and sequential patterning of the zebrafish posterior hindbrain by retinoic acid. Dev Biol 285: 593-605.

MCCLINTOCK, J.M., CARLSON, R., MANN, D.M. and PRINCE, V.E. (2001). Consequences of Hox gene duplication in the vertebrates: an investigation of the zebrafish Hox paralogue group 1 genes. Development 128: 2471-2484.

MCCLINTOCK, J.M., KHEIRBEK, M.A. and PRINCE, V.E. (2002). Knockdown of duplicated zebrafish hoxb1 genes reveals distinct roles in hindbrain patterning and a novel mechanism of duplicate gene retention. Development 129: 23392354.

MCNULTY, C.L., PERES, J.N., BARDINE, N., VAN DEN AKKER, W.M. and DURSTON, A.J. (2005). Knockdown of the complete Hox paralogous group 1 leads to dramatic hindbrain and neural crest defects. Development 132: 28612871.

MEIJER, A.H., VERBEEK, F.J., SALAS-VIDAL, E., CORREDOR-ADAMEZ, M., BUSSMAN, J., VAN DER SAR, A.M., OTTO, G.W., GEISLER, R. and SPAINK, H.P. (2005). Transcriptome profiling of adult zebrafish at the late stage of chronic tuberculosis due to Mycobacterium marinum infection. Mol Immunol 42: 1185-1203.

MOENS, C.B. and SELLERI, L. (2006). Hox cofactors in vertebrate development. Dev Biol 291: 193-206.

OUYANG, M., GARNETT, A.T., HAN, T.M., HAMA, K., LEE, A., DENG, Y., LEE, N., LIU, H.Y., AMACHER, S.L., FARBER, S.A. et al. (2008). A web based resource characterizing the zebrafish developmental profile of over 16,000 transcripts. Gene Expr Patterns 8: 171-180.

PEARSON, J.C., LEMONS, D. and MCGINNIS, W. (2005). Modulating Hox gene functions during animal body patterning. Nat Rev Genet 6: 893-904.

POSTLETHWAIT, J.H., WOODS, I.G., NGO-HAZELETT, P., YAN, Y.L., KELLY, P.D., CHU, F., HUANG, H., HILL-FORCE, A. and TALBOT, W.S. (2000). Zebrafish comparative genomics and the origins of vertebrate chromosomes. Genome Res 10: 1890-1902.
PRINCE, V.E. and PICKETT, F.B. (2002). Splitting pairs: the diverging fates of duplicated genes. Nat Rev Genet 3: 827-837.

ROHRSCHNEIDER, M.R., ELSEN, G.E. and PRINCE, V.E. (2007). Zebrafish Hoxb1a regulates multiple downstream genes including prickle1b. Dev Biol 309: 358-372.

ROSSEL, M. and CAPECCHI, M.R. (1999). Mice mutant for both Hoxa1 and Hoxb1 show extensive remodeling of the hindbrain and defects in craniofacial development. Development 126: 5027-5040.

STUDER, M., GAVALAS, A., MARSHALL, H., ARIZA-MCNAUGHTON, L., RIJLI, F.M., CHAMBON, P. and KRUMLAUF, R. (1998). Genetic interactions between Hoxa1 and Hoxb1 reveal new roles in regulation of early hindbrain patterning. Development 125: 1025-1036.

SVINGEN, T. and TONISSEN, K.F. (2006). Hox transcription factors and their elusive mammalian gene targets. Heredity $97:$ 88-96.

THISSE, B., HEYER, V., LUX, A., ALUNNI, V., DEGRAVE, A., SEILIEZ, I., KIRCHNER, J., PARKHILL, J.P. and THISSE, C. (2004). Spatial and temporal expression of the zebrafish genome by large-scale in situ hybridization screening. Methods Cell Biol 77: 505-519.

VANDEN AKKER, E., FROMENTAL-RAMAIN, C., DE GRAAFF, W., LE MOUELLIC H., BRULET, P., CHAMBON, P. and DESCHAMPS, J. (2001). Axial skeletal patterning in mice lacking all paralogous group 8 Hox genes. Development 128 : 1911-1921.

VLACHAKIS, N., CHOE, S.K. and SAGERSTROM, C.G. (2001). Meis3 synergizes with $\mathrm{Pbx} 4$ and Hoxb1b in promoting hindbrain fates in the zebrafish. Development 128: 1299-1312.

WACKER, S.A., JANSEN, H.J., MCNULTY, C.L., HOUTZAGER, E. and DURSTON A.J. (2004). Timed interactions between the Hox expressing non-organiser mesoderm and the Spemann organiser generate positional information during vertebrate gastrulation. Dev Biol 268: 207-219.

WESTERFIELD, M. (1995). The zebrafish book: a guide for the laboratory use of zebrafish (Brachydanio rerio). University of Oregon Press, Eugene.

WOLTERING, J.M. and DURSTON, A.J. (2006). The zebrafish hoxDb cluster has been reduced to a single microRNA. Nat Genet 38: 601-602. 
Further Related Reading, published previously in the Int. J. Dev. Biol.

See our Special Issue Pattern Formation edited by Cheng-Ming Chuong and Michael K. Richardson at: http://www.ijdb.ehu.es/web/contents.php?vol=53\&issue=5-6

\section{Function and specificity of Hox genes}

David Foronda, Luis F. de Navas, Daniel L. Garaulet and Ernesto Sánchez-Herrero Int. J. Dev. Biol. (2009): 1409-1419

PBX proteins: much more than Hox cofactors

Audrey Laurent, Réjane Bihan, Francis Omilli, Stéphane Deschamps and Isabelle Pellerin Int. J. Dev. Biol. (2008) 52: 9-20

Pulling forces acting on Hox gene clusters cause expression collinearity Spyros Papageorgiou

Int. J. Dev. Biol. (2006) 50: 301-308

Geometry and mechanics of teleost gastrulation and the formation of primary embryonic axes

Elena M. Cherdantseva and Vladimir G. Cherdantsev

Int. J. Dev. Biol. (2006) 50: 157-168

Transcriptional regulation and the evolution of development.

Gregory A Wray

Int. J. Dev. Biol. (2003) 47: 675-684

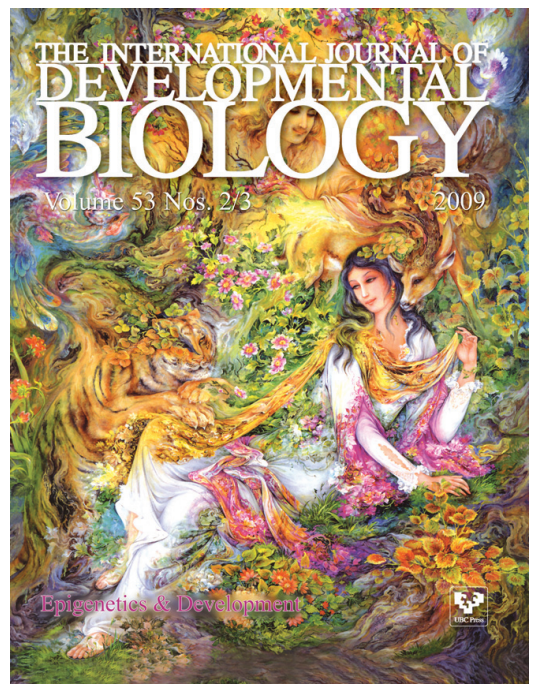

5 yr ISI Impact Factor $(2008)=3.271$

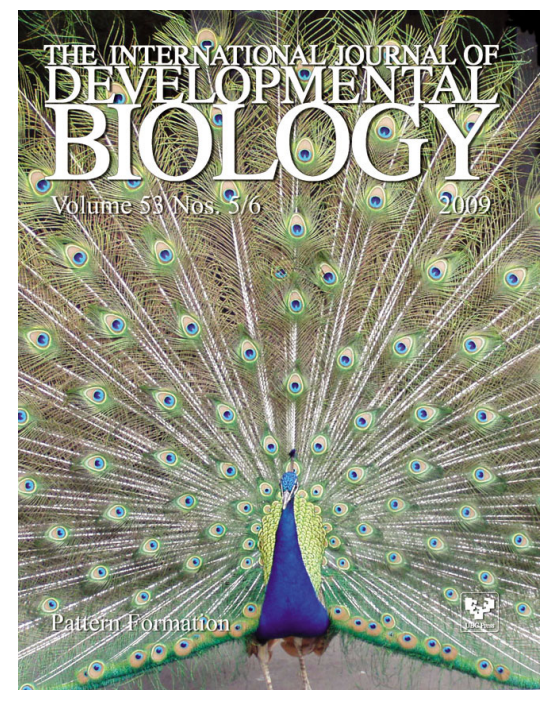

